\title{
Anthropometric indices of failure to thrive
}

\author{
Pauline Raynor, Mary C J Rudolf
}

\begin{abstract}
Aims-To compare five anthropometric methods of classifying failure to thrive in order to ascertain their relative merits in predicting developmental, dietary, and eating problems.

Methods-The five anthropometric methods were compared in 83 children with failure to thrive.

Results-The methods were inconsistent in classification of severity, and no one method was superior in predicting problems.

Conclusions-Weight alone, being the simplest, is still the most reasonable marker for failure to thrive and associated problems.
\end{abstract}

(Arch Dis Child 2000;82:364-365)

Keywords: failure to thrive; anthropometric measure; body mass index

"Failure to thrive" implies failure, not only of growth, but also of other aspects of a child's wellbeing. Identification of failure to thrive and an assessment of the severity of the nutritional state is important to identify children at risk, and to provide appropriate intervention. It is surprising therefore, that for such a common and important problem there seems to be no consistent definition.

An attempt to tackle this issue was made previously, ${ }^{2}$ when three different anthropometric methods for categorising undernutrition in childhood were applied to children with failure to thrive. The authors were unable to recommend any one method over another and

Department of Community Child Health, Belmont

House, 3 Belmont Grove, Leeds LS2 9NP, UK

P Raynor

M C J Rudolf

Correspondence to:

Dr Rudolf

email:

mrudolf@ulth.northy.nhs.uk

Accepted 15 February 2000

Table 1 Five methods used in estimating nutritional state

\begin{tabular}{ll}
\hline Method & Parameters measured \\
\hline $\begin{array}{l}\text { Gomez et al } \\
\text { Waterlow }\end{array}$ & $\begin{array}{l}\text { Child's weight (median weight for age }) \\
\text { McLaren/Read } \\
\text { Child's weight (median weight for height })\end{array}$ \\
Body mass index & $\begin{array}{l}\text { weight/median height for age }) \\
\text { Child's weight }(\mathrm{kg})\end{array}$ \\
Thrive Index & Later weight $\left(\mathrm{m}^{2}\right)$
\end{tabular}

None $\square$ Mild $\square$ Moderate $\square$ Severe

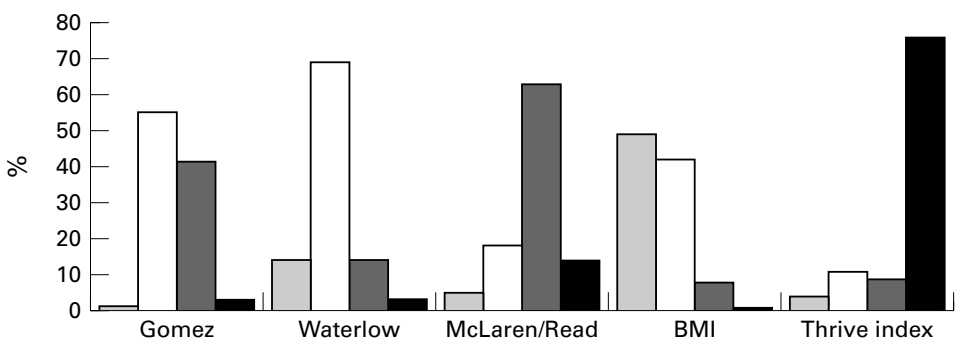

Figure 1 Classification of children with failure to thrive according to five different indices. concluded that measures other than anthropometry alone were needed to determine failure to thrive. Any such measure should ideally correlate with problems commonly associated with failure to thrive, namely developmental delay, poor diet, and eating difficulties.

We determined to take this work further by relating five anthropometric measures with data we had on the developmental, dietary, and behavioural characteristics of children with failure to thrive.

\section{Methods}

We received data on children enrolled in a randomised controlled trial of health visitor intervention in failure to thrive, ${ }^{3}$ calculating anthropometric indices for all children using five methods as shown in table 1 . For calculation of the three first methods, median height and weight were taken as the 50th centile of the 1990 growth standards. ${ }^{4}$ Body Mass Index $(B M I)^{5}$ values were converted into SD scores and the Thrive Index was calculated using the appropriate formula ${ }^{6}$ based on the same standards.

Cognitive and psychmotor development were ascertained using the Bayley Scales of Infant Development II . The energy intake and the percentage expected average requirement (EAR) were calculated for the first 34 children entering the study from a four day food diary followed by an interview by a research dietitian. Eating behaviour scores were ascertained from a self administered questionnaire as described previously. $^{3}$

Linear regression was used to determine the relation between each anthropometric index, and development, energy intake, and eating problem score. Results were compared to evaluate which method was most predictive of problems associated with failure to thrive.

\section{Results}

Growth measurements were available for 83 children. The degree of failure to thrive of the sample varied greatly according to the index used (fig 1). For example, 85\% were moderately or severely undernourished using the Thrive Index, $77 \%$ according to McLaren and Read, $17 \%$ by Waterlow's classification, and $8 \%$ using BMI.

Many of the children were developmentally delayed. Forty six per cent had a Mental Developmental Index (MDI) less than 85, of whom $12 \%$ were severely delayed (MDI <70). Fifty four percent had a Psychomotor Developmental Index (PDI) less than 85, of whom $27 \%$ had severe delay (PDI <70). There was no correlation between degree of undernutrition and developmental scores for any of the five methods. 
Fifteen of the 34 children whose diet was analysed were found to be receiving less than $85 \%$ of the EAR for their age. There was no correlation between EAR and degree of undernutrition for any of the five methods, nor was there a correlation for eating problem scores.

\section{Discussion}

Poor growth in childhood is a marker for a variety of psychosocial and medical problems. For this reason growth monitoring is a component of child health surveillance programmes worldwide. In general, weight gain is used as the measure for identifying babies and young children who are failing to thrive, and it is generally assumed that the more severely underweight, the worse the prognosis. Less commonly length is utilised in interpreting the significance of a child's weight.

Like Wright and colleagues, ${ }^{2}$ we found that the three methods they studied varied widely in categorising children, with some identified as moderately or severely failing to thrive by one method, and normal or mild in another. This is not really surprising as a short child with appropriate weight according to Gomez would be identified as failing to thrive, whereas the same child would be considered adequately nourished by the methods of Waterlow, by BMI, and possibly McLaren Read too.

The value of any index of failure to thrive would lie in its usefulness in identifying the child at risk and predicting the severity of other nutrition related problems, which may be present. By extending the work of Wright and colleagues, ${ }^{2}$ and including BMI and the Thrive Index in our analyses we were able to examine if any one method correlated better than another with developmental delay and dietary intake.

Although the high prevalence of developmental delay and inadequate diets indicated that this was a group of children at risk, no association was found between the severity of problems and the degree of undernutrition for any of the indices studied. We argue, therefore, that if no one marker is more predictive than another, we may as well continue to use weight alone as a measure of failure to thrive. This can either be ascertained using the Gomez calculation, weight SD scores, or simply position on the weight chart. There seems to be no extra value in including height in the computation.

In short, there is no simple anthropometric measure which highlights the degree of risk for a child. There is no substitute for clinical skills and acumen to ascertain which child is failing to thrive, and how severely, and which child is simply showing growth faltering or is normally small. The paediatrician's evaluation, taking into account growth over time, development and dietary status, as well as psychosocial factors, is essential when determining the severity of failure to thrive in children.

Sources of financial assistance: Northern and Yorkshire Regional Health Authority and the Leeds Community and Mental Health Trust.

1 Wilcox WD, Nieburg P, Miller DS. Failure to thrive. A continuing problem of definition. Clin Pediatr 1989;28:391-4.

2 Wright JA, Ashenburg C, Whitaker RC. Comparison of methods to categorize undernutrition in children. Pediatrics 1994;24:944-6.

3 Raynor P, Rudolf MCJ, Cooper K, Marchant P, Cottrell D. A randomised controlled trial of specialist health visitor intervention for failure to thrive. Arch Dis Child 1999;80: $500-6$.

4 Freeman JV, Cole TJ, Jones PRM, White EM, Preece MA. Cross sectional stature and weight reference curves for the UK, 1990. Arch Dis Child 1995;73:17-24.

5 Cole TJ, Freeman JV, Preece MA. Body mass index reference curves for the UK, 1990. Arch Dis Child 1995;73: 25-9.

6 Wright CM, Avery A, Epstein M, Birks E, Croft D. New charts to evaluate weight faltering. Arch Dis Child 1998;78: $40-3$. 